\title{
Chromosome Number, Meiosis and Pollen Fertility in Vicia rigidula Royle and $V$. tenera Grah. From Cold Desert Regions of India
}

\author{
Dalvir Kaur and Vijay Kumar Singhal* \\ Department of Botany, Punjabi University, Patiala-147002, Punjab (India) \\ Received December 5, 2009; accepted January 5, 2010
}

\begin{abstract}
Summary We have recorded the meiotic chromosome counts in 2 species, Vicia rigidula $(n=12)$ and $V$. tenera $(n=7)$ from the cold desert region of Kinnaur district of Himachal Pradesh (India). $V$. rigidula which exists at tetraploid level $(x=6)$ and depicts the phenomenon of cytomixis involving chromatin transfer in $6.52 \%$ of the observed pollen mother cells (PMCs) during different meiotic stages. 3.43-12.20\% of PMCs also show non-synchronous disjunction of a few bivalents, laggards and chromatin bridges during anaphases/telophases, and micronuclei and included micronuclei in tetrads. Products of such aberrant PMCs result in the formation of sterile/unstained pollen grains and fertile/stained pollen grains of variable sizes. The meiotic course in V. tenera, which is diploid $(x=7)$, depicts normal meiotic behaviour in the majority of the PMCs. Only a few PMCs $(0.20-1.20 \%)$ depict some meiotic disturbances during anaphases resulting in the formation of $6.00-7.20 \%$ sterile/unstained pollen grains.
\end{abstract}

Key words Chromosome number, Cytomixis, Meiotic irregularities, Vicia rigidula, V. tenera.

The genus Vicia L., Tribe: Vicieae, Family: Fabaceae with 190 species (ILDIS 1999) is distributed in Europe, Asia and North America, extending to the temperate regions of South America and Tropical Africa (Maxted 1993). In India species of the genus Vicia are distributed in the temperate zones of Western Himalaya and the Northern plains. Many species of the genus are cultivated for food and fodder (Cremonini et al. 1998). Maxted et al. (1991) have divided the genus Vicia into 2 subgenera: Vicilla and Vicia with 17 and 9 sections, respectively. Most of the species of the genus are annuals, but a few of them are perennials. V. rigidula Royle is a perennial subglabrous climber with 2-3 inch long leaves ending in intricate tendrils and with golden yellow flowers appearing during June to September. The species is found in the temperate regions of Western Himalaya between altitudes of $1500-3000 \mathrm{~m}$. V. tenera Grah. grows as a perennial subglabrous climber with pinnate leaves and pinkish-purple flowers which appear during May-July. The species is distributed at elevations of $1800-2600 \mathrm{~m}$ in moist shady places.

Perusal of chromosomal data on the basis of information gathered from Index to Plant Chromosome Numbers (1976-2006) and other authors (Srivastava 1963, Raina and Bisht 1988, Kumari and Bir 1990, Nikiforova 1990, Maxted et al. 1991, Venora et al. 1991, Akpinar and Bilaloglu 1997, Bisht et al. 1998, Kamel 1999, Bagci and Sahin 2000, Kotseruba et al. 2000, Rahiminejad et al. 2000, Tabur et al. 2000, 2002) reveals that a large number of species of the genus Vicia are yet to be known chromosomally, especially those from the high altitudinal regions and cold deserts of Indian Himalayas. We have worked out the chromosome counts in $V$. rigidula and $V$. tenera collected in Kinnaur district of Himachal Pradesh. Simultareously, we have also recorded our observations on male meiotic course, pollen sterility and pollen grain size in these species.

*Corresponding author, e-mail: vksinghal53@gmail.com 


\section{Materials and methods}

For cytological studies, wild plants of $V$. rigidula Royle and $V$. tenera Grah. were collected from the cold regions of the Kinnaur district of Himachal Pradesh during the months of June-July 2008. Voucher specimens of the worked-out plants were deposited in the Herbarium of the Department of Botany, Punjabi University, Patiala (PUN). Floral buds of variable sizes ranging from $1-18 \mathrm{~mm} \times 0.5-5 \mathrm{~mm}$ were fixed in Carnoy's fixative for $24 \mathrm{~h}$ and preserved in $70 \%$ alcohol at $4^{\circ} \mathrm{C}$. For male meiotic studies, the anthers from flowers of size ranging from $2-5 \mathrm{~mm} \times 0.5-2 \mathrm{~mm}$ were squashed in $1 \%$ acetocarmine. A number of slides were carefully examined for chromosome counts and meiotic analysis in each species. For male meiotic analysis, 590-650 PMCs ( . rigidula) and 415-458 PMCs ( $V$. tenera) at different stages of meiosis were observed. Pollen grain fertility was estimated through stainability for which the mature anthers from different flowers of sizes ranging from $13-18 \mathrm{~mm} \times 4-5 \mathrm{~mm}$ were squashed in $1 \%$ aniline blue in lactophenol solution and glycerol-acetocarmine $(1: 1)$ mixture. A total of 835-899 pollen grains ( $V$. rigidula) and 590-732 pollen grains $(V$. tenera) were observed for the estimation of pollen fertility. Well filled and stained pollen grains were scored as apparently fertile and poorly stained/unstained pollen grains were counted as sterile. Pollen grain size was measured using occulomicrometre. Photomicrographs of PMCs, tetrads and pollen grains were made from the freshly prepared slides using the Nikon $80 i$ eclipse microscope and Leica Qwin Digital Imaging System.

\section{Results}

\section{V. rigidula Royle}

The male meiotic studies were carried out in 2 plants (PUN 50919, 51044) collected from the roadside in the Kalpa region, growing at $31^{\circ} 31^{\prime} \mathrm{N}, 78^{\circ} 15^{\prime} \mathrm{E}$ latitude and at $2760 \mathrm{~m}$ altitude in Kinnaur district of Himachal Pradesh. Both the individuals scored through male meiosis uniformly reveal the same haploid chromosome count of $n=12$ (Fig. 1) indicating that the species was tetraploid based on $x=6$. The chromosomes, which are large-sized, could not be counted clearly during the late prophase I and metaphase I (Fig. 2) due to stickiness in chromatin material and interbivalent connections (Figs. 3, 4) as observed in majority of the PMCs. The meiotic chromosomes number in the species is confirmed in only a few PMCs at anaphase I/metaphase II with 12:12 chromosomes at each pole (Fig. 5). The meiotic course in majority of the observed

Figs. 1-20. Meiotic chromosomes, meiotic abnormalities and pollen grains in Vicia rigidula (1-14) and $V$. tenera (15-20). 1. A PMC showing 12 bivalents at metaphase I. (PUN 50919), 2. A PMC showing uncountable bivalents at metaphase I. (PUN 50919), 3. A PMC showing interbivalent connections (arrowed) at late prophase I. (PUN 51044), 4. A PMC showing interbivalent connections (arrowed) at metaphase I. (PUN 50919), 5. A PMC showing 12:12 chromosomes distribution at metaphase II. (PUN 51044), 6. PMCs showing chromatin transfer (arrowed) during early prophase I and 1 of the PMC showing extra chromatin material (arrow head). (PUN 50919), 7. Two PMCs showing chromatin transfer (arrowed) at telophase I. (PUN 50919), 8. A PMC with laggards (arrowed) at anaphase I. (PUN 50919), 9. A PMC with laggards (arrowed) at telophase I. (PUN 51044), 10. A PMC with lagging chromatin material (arrowed) at telophase II. (PUN 50919), 11. A PMC with chromatin bridges (arrowed) at anaphase I. (PUN 50919), 12. A tetrad with 1 micronucleus (arrowed). (PUN 51044), 13. A tetrad with micronuclei (arrowed) and included micronuclei (arrow head). (PUN 50919), 14. Apparently fertile heterogeneously sized pollen grains. (PUN 50919), 15. A PMC showing 7 bivalents at metaphase I. (PUN 50920), 16. A PMC showing 7:7 chromosomes distribution at anaphase I. (PUN 51952), 17. A PMC with non-synchronous disjunction of 2 bivalents (arrowed) at anaphase I. (PUN 51950), 18. A PMC with 1 laggard (arrowed) at anaphase I. (PUN 51951), 19. A PMC with chromatin bridges (arrowed) at anaphase I. (PUN 51950), 20. Fertile and sterile pollen grains. (PUN 51950). Scale bar $=10 \mu \mathrm{m}$. 
PMCs (81.28-96.57\%) is regular resulting into normal tetrad formation. However, in 1 individual, $6.52 \%$ of the observed PMCs depict abnormal meiotic course due to the phenomenon of cytomixis involving chromatin transfer among proximate meiocytes during the different stages of meiosis (Figs. 6, 7, Table 1). The chromatin migration among the adjacent meiocytes occurs through cytoplasmic channels. As a consequence of chromatin transfer, several PMCs with aneuploid chromosome numbers and extra chromatin material are observed (Fig. 6). Besides, 3.43-12.20\% PMCs are also observed to show non-synchronous disjunction of some bivalents, the presence of 3-4 laggards (Figs. 8-10) and chromatin bridges (Figs. 11) at anaphases/telophases, micronuclei (Fig. 12) and included micronuclei in tetrads (Fig. 13). These meiotic abnormalities consequently result into some pollen sterility (19.00-19.65\%) and 2 different sized fertile pollen grains as normal (37.70 $\mu \mathrm{m} \times 22.62 \mu \mathrm{m} ; 96.15 \%)$ and small-sized (26.39 $\mu \mathrm{m} \times 18.85 \mu \mathrm{m} ; 3.85 \%)$ (Fig. 14).
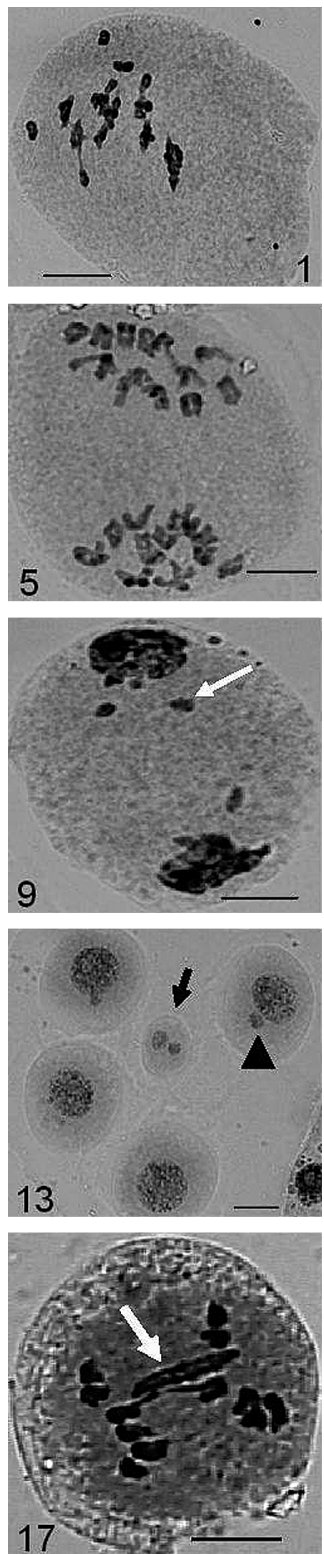
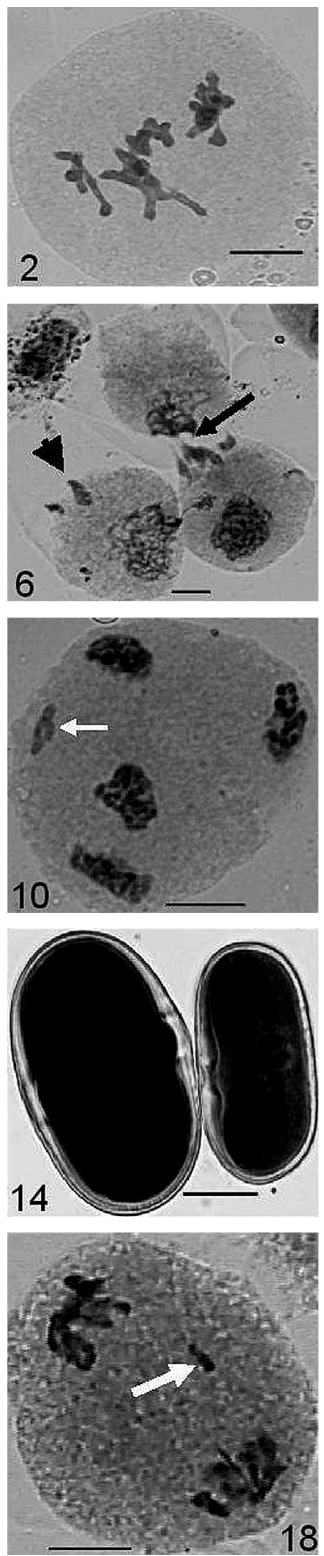
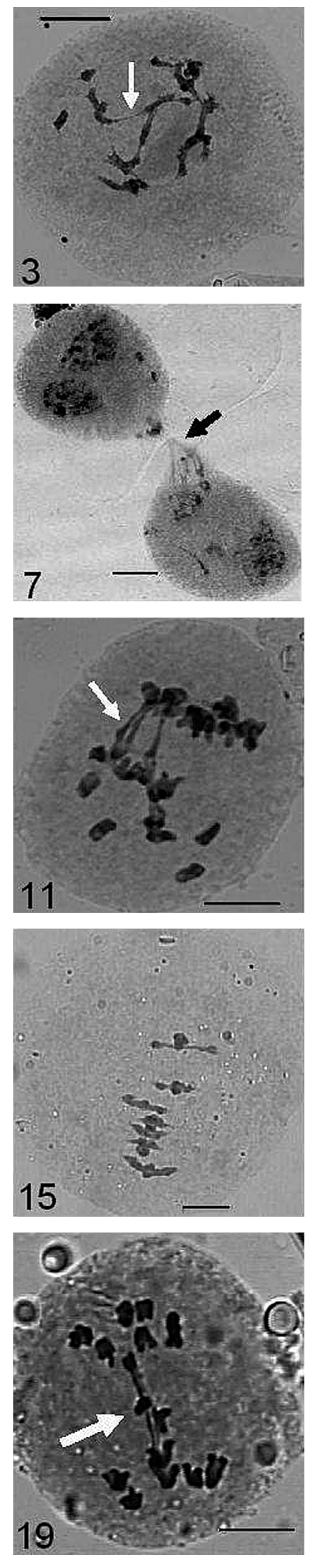
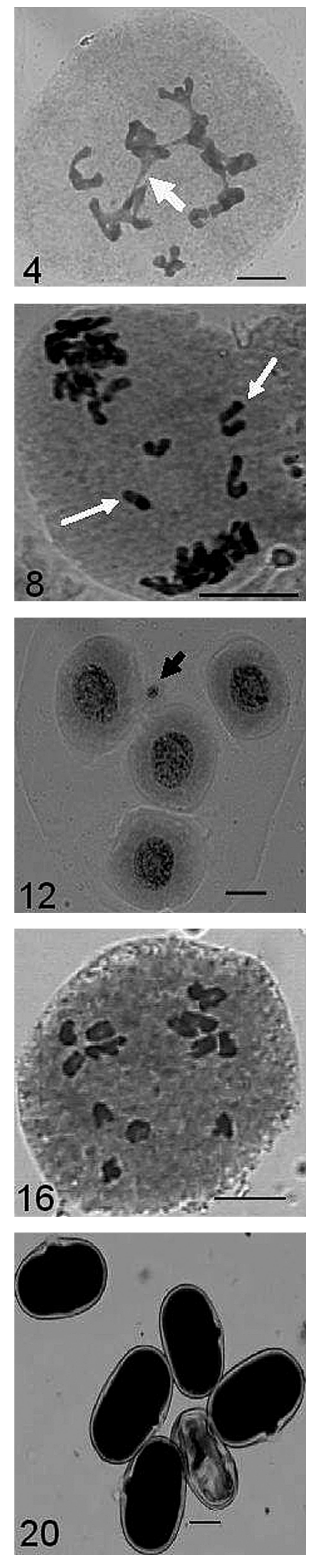


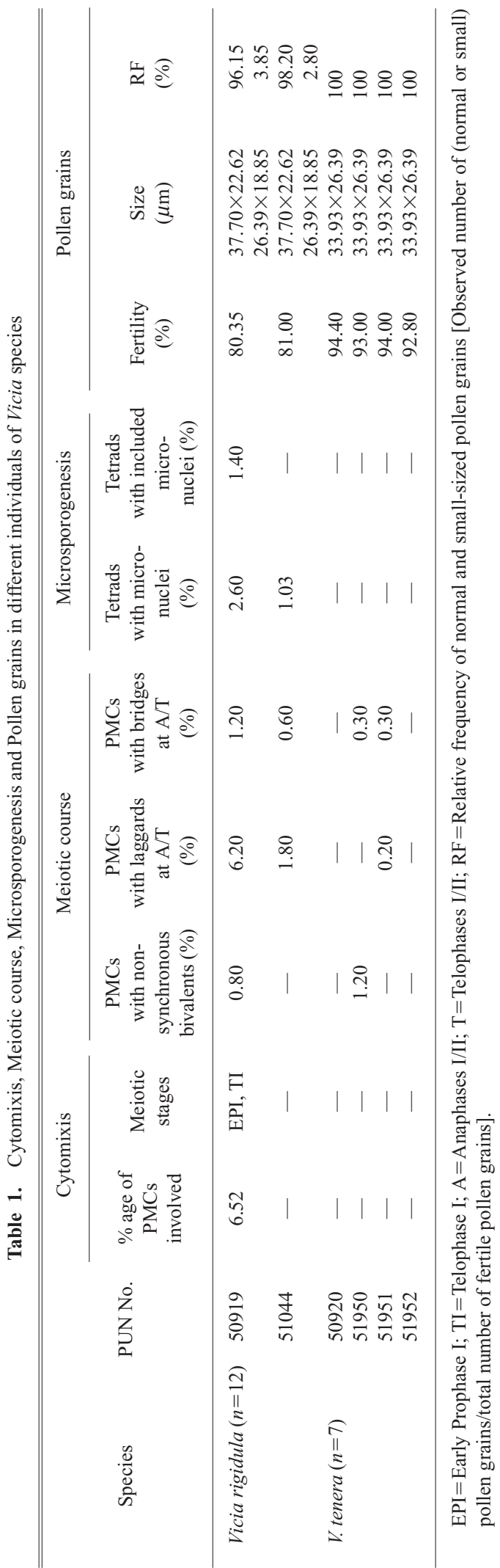

\section{V. tenera Grah.}

The chromosome number is observed on male meiosis from 4 plants (PUN 50920, 51950, 51951, 51952) collected from moist places along cultivated fields in the Sangla region $\left(31^{\circ} 25^{\prime} \mathrm{N}, 78^{\circ} 15^{\prime} \mathrm{E}\right.$ latitude and 2680 $\mathrm{m}$ altitude) of the Kinnaur district (Table 1). All the plants share the same chromosome number of $n=7$ as confirmed from the uniform presence of 7 relatively small-sized bivalents at metaphase I (Fig. 15) and 7:7 chromosomes distribution at each pole during anaphase I (Fig. 16). In the majority of the observed PMCs, meiotic course up to the tetrad formation is recorded to be normal. However, a few PMCs $(0.20-1.20 \%)$ are observed to show the presence of non-synchronous disjunction of 1-2 bivalents (Fig. 17), 1-2 laggards (Fig. 18) and chromatin bridges during anaphase I (Fig. 19). Consequent to these meiotic abnormalities, some sterile/unstained pollen grains $(6.00-7.20 \%)$ are resulted in the species (Fig. $20)$. The fertile/stained pollen grains, however, were noticed to be of uniform size (33.93 $\mu \mathrm{m} \times 26.39 \mu \mathrm{m})$.

\section{Discussion}

Chromosome information gathered on the genus Vicia reveals that 193 species, inclusive of 69 species from India, are known chromosomally (Darlington and Wylie 1955, Love and Love 1966, 1974, 1975, Fedorov 1969, Moore 1973, 1974, 1977, Goldblatt 1984, 1985, 1988, Kumar and Subramanian 1986, Goldblatt and Johnson 1990, 1991, 1994, 1996, 1998, 2000, 2003, Index to Plant Chromosome Numbers 2006). To this list, we here add 2 more species, $V$. rigidula $(n=12)$ and $V$. tenera $(n=7)$. An analysis of chromosome records in the genus reveals that majority of the species are diploid at basic numbers of $x=5,6,7$ while 25 species exist at tetraploid or hexaploid level. 48 species are counted to depict the existence of chromosomal variation due to intraspecific polyploidy and aneuploidy. Among the different basic numbers, $x=7$ with 122 species is the most common followed by $x=6$ (79 species). Only 29 species depict $x=5$ 
as the basic number. Species depicting dibasic $(x=5,6 ; 8$ species, $x=6,7 ; 18$ species and $x=5,7 ; 1$ species) and 3 basic numbers $(x=5,6,7 ; 5$ species) also exist. Based on $x=6, V$. rigidula with $2 n=24$ exists at tetraploid level while $V$. tenera with $2 n=14$ exists at diploid level $(x=7)$. The meiotic course in $V$. rigidula is characterized by the presence of the phenomenon of cytomixis involving chromatin transfer and associated meiotic abnormalities, resulting into some pollen sterility and heterogenous-sized, apparently fertile/stained pollen grains. Similar observations regarding the effect of chromatin transfer and associated meiotic abnormalities on reduced pollen fertility and formation of variable sized pollen grains have been reported in Vicia faba (Haroun et al. 2004), Caltha palustris (Kumar and Singhal 2008), Clematis flammula (Kumar et al. 2008), Meconopsis aculeata (Singhal and Kumar 2008a), Withania somnifera (Singhal and Kumar 2008b), Hippophae rhamnoides (Singhal et al. 2008), Lychnis indica (Singhal et al. 2009a), Anemone rivularis (Singhal et al. 2009b), Carthamus tinctorius (Sheidai et al. 2009a) and species of Alopecurus and Catbrosa (Sheidai et al. 2009b). Male meiosis in V. tenera, which is a diploid, depicts almost normal meiotic course and high pollen fertility and uniform sized fertile pollen grains. The presence of some meiotic disturbances during anaphase resulting in some pollen sterility in $V$. tenera might be the consequence of abnormal spindle activity during chromosome distribution.

\section{Acknowledgements}

The authors are grateful to the University Grants Commission, New Delhi for providing financial assistance under the DRS SAP I \& II and ASIST programme and DK is also grateful to UGC for providing fellowship under Rajiv Gandhi National Fellowship Scheme. Thanks are also due to the Head of the department of Botany for the necessary laboratory and library facilities.

\section{References}

Akpinar, N. and Bilaloglu, R. 1997. Cytological investigations of certain species of Vicia L. Turk. J. Biol. 21: 197-207. Bagci, E. and Sahin, A. 2000. A numerical cytotaxonomic study on some Vicia L. taxa. Ot. Syst. Bot. Derg. 7: 143-160.

Bisht, M. S., Kesavacharyulu, K. and Raina, S. N. 1998. Nucleolar chromosome variation and evolution in the genus Vicia. Caryologia 51: 133-147.

Cremonini, R., Miotto, D., Ngu, M. A., Tota, D., Pignone, D., Blangiforti, S. and Venora, G. 1998. Cytology of Vicia species. 5. Nuclear chromatin structure, karyomorphological analysis and DNA content in newly discovered relatives of Vicia faba L.: Vicia kalakhensis Khattab, Maxted et Bisby and Vicia eristalioides Maxted. Cytologia 63: 371-379.

Darlington, C. D. and Wyile, A. P. 1955. Chromosome Altas of Flowering Plants. George Allen and Unwin Ltd., London.

Fedorov, A. A. 1969. Chromosome Numbers of Flowering Plants. Academy of Sciences of the USSR, Komarov Botanical Institute, Leningrad (Reprint 1974).

Goldblatt, P. 1984, 1985, 1988. Index to Plant Chromosome Numbers. 1979-1981, 1982-1983, 1984-1985. Monogr. Missouri Bot. Gard. 8, 13, 23.

Goldblatt, P. and Johnson, D. E. 1990, 1991, 1994, 1996, 1998, 2000, 2003. Index to Plant Chromosome Numbers. 1986-1987, 1988-1989, 1990-1991, 1992-1993, 1994-1995, 1996-1997, 1998-2000. Monogr. Missouri Bot. Gard. 30, 40, 51, 58, 69, 81, 94 .

Haroun, S. A., A1 Shehri, A. M. and A1 Wadie, H. M. 2004. Cytomixis in microsporogenesis of Vicia faba L. (Fabaceae). Cytologia 69: 7-11.

Index to Plant Chromosome Numbers 1979-2006. P. Goldblatt \& D. E. Johnson, eds. Missouri Botanical Garden, St Louis. http://mobot.mobot.org/W3T/Search/ipcn.html.

ILDIS. 1999. http://www.ildis.org.

Kamel, E. A. 1999. Karyological studies on some taxa of genus Vicia L. (Fabaceae). Cytologia 64: 441-448.

Kotseruba, V. V., Venora, G., Blangiforti, S., Castiglione, M. R. and Cremonini, R. 2000. Cytology of Vicia species. IX. Nuclear DNA amount, chromatin organization and computer aided karyotyping of a Russian accession of Vicia faba L. Caryologia 53: 195-204.

Kumar, P. and Singhal, V. K. 2008. Cytology of Caltha palustris L. (Ranunculaceae) from cold regions of Western 
Himalayas. Cytologia 73: 137-143.

Kumar, P., Singhal, V. K. and Kaur, J. 2008. Cytomixis induced meiotic abnormalities in pollen mother cells of Clematis flammula L. (Ranunculaceae). Cytologia 73: 381-385.

Kumar, V. and Subramanian, B. 1986. Chromosome Atlas of Flowering Plants of the Indian Sub-continent Vol. I. Dicotyledons. B. S. I., Calcutta.

Kumari, S. and Bir, S. S. 1990. Karyomorphological evolution in Papilionaceae. J. Cytol. Genet. 25: 173-219.

Love, A. and Love, D. 1966. Cytotaxonomy of the alpine vascular plants of mount Washington. Univ. Colorado Studies, Ser. Biol. 24: 1-74.

— and - 1974. Cytotaxonomical Atlas of the Solvenian Flora. J. Cramer, Lehre.

— and - 1975. Cytotaxonomical Atlas of Arctic Flora. J. Cramer, Vantus.

Maxted, N. 1993. A phenetic investigation of Vicia L. subgenus Vicia (Leguminosae, Vicieae). Bot. J. Linn. Soc. 111: 155-182.

Maxted, N., Callimassia, M. A. and Bennett, M. D. 1991. Cytotaxonomic studies of Eastern Mediterranean Vicia species (Leguminosae). Plant Syst. Evol. 177: 221-234.

Moore, R. J. 1973, 1974, 1977. Index to Plant Chromosome Numbers 1967-1971, 1972, 1973-1974. Regnum Veg. 90, 91, 96.

Nikiforova, O. D. 1990. Chromosome numbers in some Siberian species of the genera Vicia (Fabaceae) and Beckmannia (Poaceae). Bot. Z. 75: 121

Rahiminejad, M. R., Ethemam, M. H., and Neishaboori, A. 2000. Cytotaxonomic studies of some Iranian Vicia species (Fabaceae). J. Sci. 11: 1-5.

Raina, S. N. and Bisht, M. S. 1988. DNA amounts and chromatin compactness in Vicia. Genetica 77: 65-77.

Sheidai, M., Sotoode M. and Nourmohammadi. 2009a. Chromosome pairing and cytomixis in Safflower (Carthamus tinctorius L., Asteraceae) cultivars. Cytologia 74: 43-53.

- Jafari, S., Taleban, P. and Keshavarzi, M. 2009b. Cytomixis and unreduced pollen grain formation in Alopecurus L. and Catbrosa Beauv. (Poaceae). Cytologia 74: 31-41.

Singhal, V. K. and Kumar, P. 2008a. Impact of cytomixis on the meiosis, pollen viability and pollen size in wild populations of Himalayan poppy (Meconopsis aculeata Royle). J. Biosci. 33: 371-380.

— and - 2008b. Cytomixis during microsporogenesis in the diploid and tetraploid cytotypes of Withania somnifera (L.) Dunal, 1852 (Solanaceae). Comp. Cytogenet. 2: 85-92.

- Kaur, D. and Kumar, P. 2008. Effects of cytomixis on pollen size in 'Seabuckthorn' (Hippophae rhamnoides L., Elaeagnaceae). Cytologia. 73: 167-172.

—, Kaur, S., Kaur, D. and Kumar, P. 2009a. New detection of haploid chromosomes, pollen size and sterility in Lychnis indica Benth. var. fimbriata Wall. Chrom. Bot. 4: 53-56.

—, Kumar P., Kaur, D. and Rana, P. K. 2009b. Chromatin transfer during male meiosis resulted into heterogeneous sized pollen grains in Anemone rivularis Buch.-Ham. ex DC. from cold deserts. Cytologia 74: 229-234.

Srivastava, L. M. 1963. Cytological studies in certain species of Vicia. Cytologia 28: 154-169.

Tabur, S., Civelek, S. and Bagci, E. 2000. Cytotaxonomic studies on some Vicia L. species growing in eastern Mediterranean and southern Aegean regions, I. Acta Bot. Gall. 148: 159-174.

—, - and - 2002. Cytotaxonomic studies on some Vicia L. species growing in eastern Mediterranean and southern Aegean regions, II. Acta Bot. Hung. 44: 185-204.

Venora, G., Blangiforti, S., Ruffini Castiglione, M., Black-Samuelsson, S. and Cremonini, R. 1991. Cytology of Vicia species. VIII. Nuclear DNA contents, chromatin organization and karyotype evolution in Vicia pisiformis L. populations. Caryologia 52: 105-115. 